\title{
Structure and meaning of tears
}

\section{Carlo V Bellieni*}

Department of Pediatrics, University of Siena, Italy

Tears have a specific content in salts, hormones, water and antibodies. This has been showed by recent researches, that also proposed hypotheses on their utility for humans, the only mammals that produce tears for psychological purposes. Tears have been supposed to be less frequent in adult males for evolutionary reasons: men's cheeks are less sensible to the tears' strokes than women's, for being hairy or more exposed to physical agents (cold, sun). Newborns are supposed to be immune from producing tears because their constant prone position doesn't allow tears to massage their cheeks.

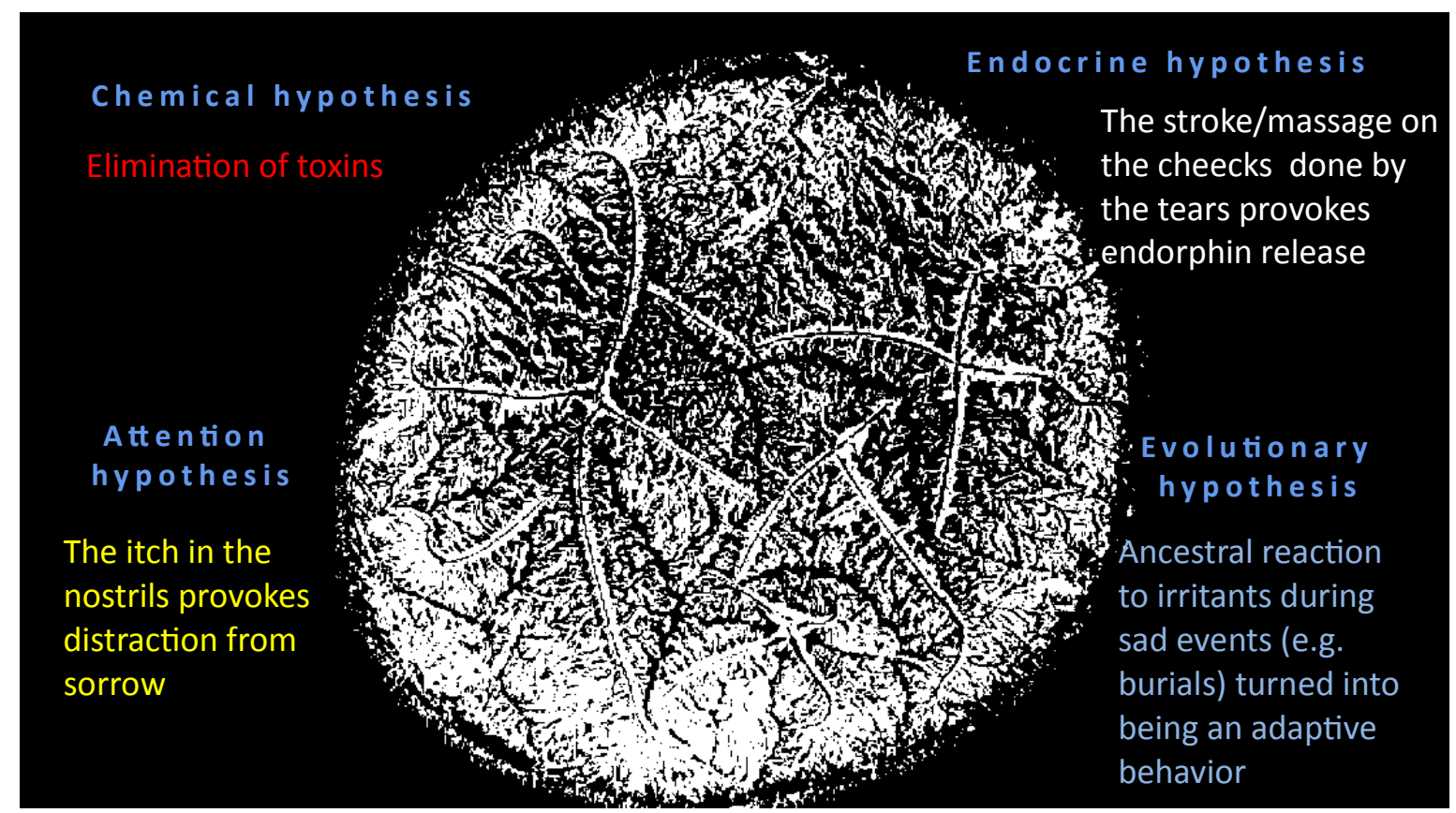

Figure 1. A human tear under the microscope (1x150). Here we report the main hypotheses on the meaning and origin of human psychological tearing.

Copyright: (C2017 Bellieni CV. This is an open-access article distributed under the terms of the Creative Commons Attribution License, which permits unrestricted use, distribution, and reproduction in any medium, provided the original author and source are credited.
Correspondence to: Carlo Valerio Bellieni, Medical Director, Department of Pediatrics, University of Siena, Italy, Tel: 0039-347 357-4566, Fax: 00390577586182, E-mail: cvbellieni@gmail.com

Received: March 02, 2017; Accepted: March 09, 2017; Published: March 13, 2017 